University of Heidelberg

Department of Economics

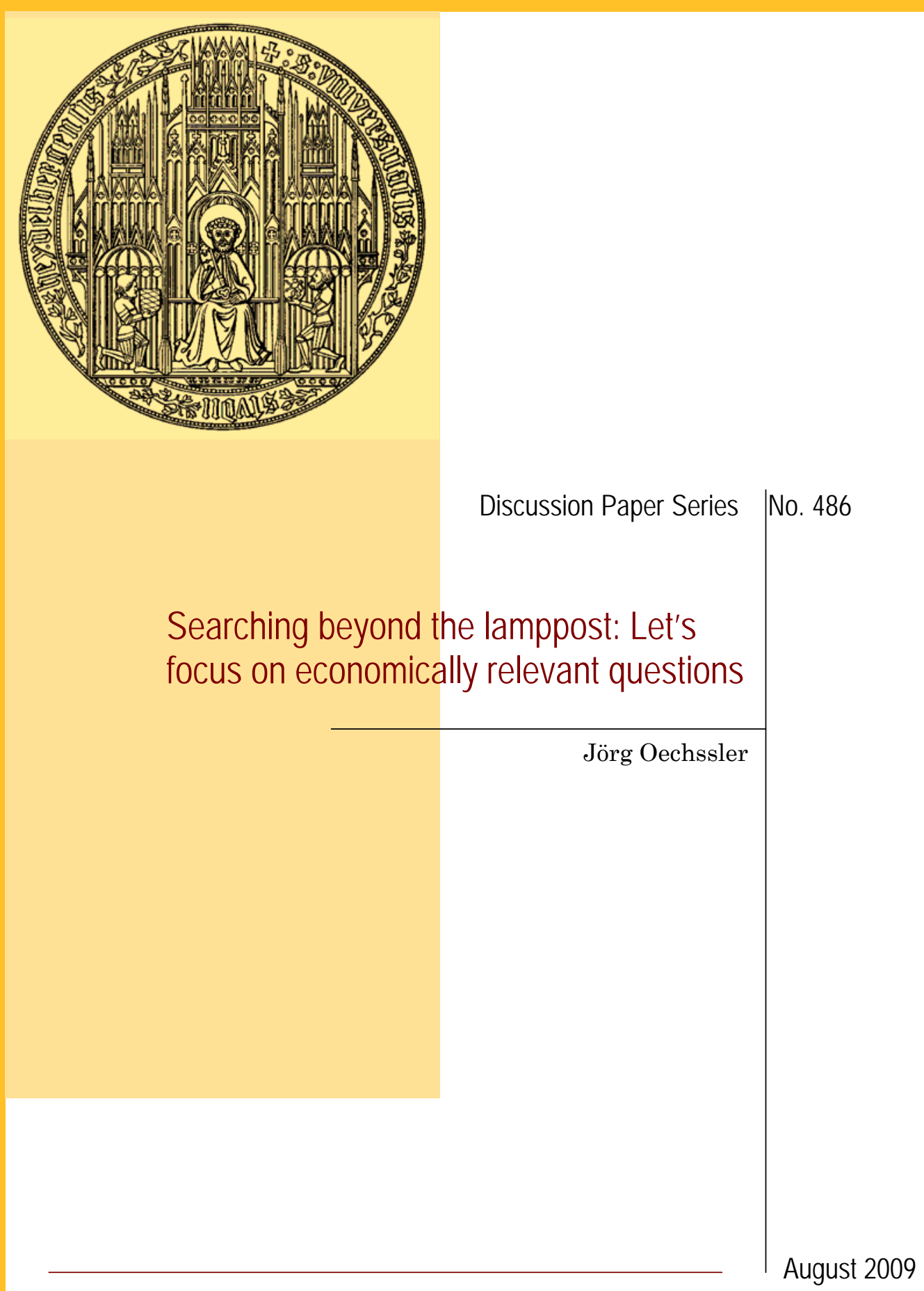




\title{
Searching beyond the lamppost: Let's focus on economically relevant questions
}

\author{
Jörg Oechssler ${ }^{1}$
}

August, 2009

It is difficult to disagree with Vernon Smith's (2010) assessment of the state of the art in experimental economics. It is informed by the experience of someone who was there, right at the beginning of experimental economics. Some of the problems he discusses, like the frequent failure of backward induction, the often overlooked influence of context, and the blurry distinction of stage games vs. repeated games, are well known and - I think - appreciated in the field. Others, like the "Other-people's money"-problem are new and thought-provoking challenges to experimental economics that have only begun to be addressed by researchers.

I will use this opportunity to argue for a reorientation of experimental economics towards new and economically relevant questions. Like Vernon Smith (2010) I shall ask "Why so many experiments on seemingly narrow topics?" but I will give a very different answer. I do appreciate the view that science has to progress in small steps, that you have to add one detail at a time to an existing design, that you want to "reduce error" by testing "a blizzard of narrowly prescribed circumstances that are not part of the theory." Yet I am afraid that we are wasting our time (and endangering the respect that other economists have for experimentalists) by playing too much with some of our favorite toys.

\section{Searching under the lamppost}

Experimental economics is in danger of behaving like the famous drunk who searches for his keys under the light even though he lost them in some dark corner. I shall pick two examples which are discussed by Vernon Smith. They may constitute relatively extreme cases but by no means are they

\footnotetext{
${ }^{1}$ Department of Economics, University of Heidelberg, email: oechssler@uni-hd.de.
} 
exclusive examples for "lampposting". Those two examples are the experimental literatures on the dictator game and on bubbles in asset markets.

\section{Please, not another dictator game!}

Historically and logically, the first dictator game experiment made a lot of sense. It was a very cute variation of the ultimatum game that allowed to discriminate among competing theories that tried to explain behavior in the ultimatum game. ${ }^{2}$ But taking it in isolation, one really has to wonder. Vernon Smith (2010) puts it very nicely:

From the perspective of the subjects, however, the dictator game task must seem strange. You are recruited to the lab, awarded a costless right to some of the experimenter's money, and given an opportunity to transfer any part or none of it to a second anonymous person who has nothing to do except receive the money. (It is not the standard interactive game in which payoffs jointly depend on the decisions of both players). "The Gods must be crazy!"

What can economists learn from this experiment? Not much, I guess. The percentage of subjects who give nothing to the other subject can be as low as $10 \%$ or less ${ }^{3}$ if subjects play with "other people's money" or can be as high as $100 \%$ if it is the proposer's money (Oxoby and Spraggon, 2008). I am sure, if someone runs an experiment where the receiver is a hungry-looking child with begging eyes, the percentage of proposers who give nothing approaches 0 . Thus we learn that - depending on the context the percentage of proposers who give something positive can range between

\footnotetext{
${ }^{2}$ Many theorists would probably argue that there are also way too many experiments on the ultimatum game (and I have to plead guilty to adding one more, my first ultimatum game experiment, Oechssler et al. 2008). Yet, although the ultimatum game is extremely simple, it has many applications, at least as a subgame of more complex situations, e.g. in principal-agent and bargaining models, and it has profoundly shaped the way we think about those situations.

${ }^{3}$ The average percentage of zero-offers in Oxoby and Spraggon's (2008) "receiver earning treatment" is $8.43 \%$.
} 
0 and $100 \%$. Existing theories generally don't account for context and this is a good thing. Economists are not in the business of producing models that apply to an extremely narrow set of circumstances.

So the question is, why run dictator game experiments? No one seriously argues that we need the experiments to predict what could happen in real world situations. An experiment could have value in shaping the future development of theory. But the only fact that consistently emerges from dictator game experiments is that not everyone is always completely selfish, and this does not come as a big surprise. Finally, given the variability in experimental results, using the dictator game to calibrate social preferences seems silly. So maybe we should allocate our time and money to better uses.

\section{Asset markets with realistic features}

In the typical asset market experiment, as pioneered by Smith et al. (1988), bubbles occur even in a very austere environment. Usually one asset is traded for a finite (often 10 or 15) number of trading periods. After each period a stochastic dividend is paid. Thus, the fundamental value of the asset is declining since it is given by the expected value of the dividend times the number of remaining periods. Nevertheless, Smith et al. observed constant or even increasing prices followed by crashes at the end of the experiment (see Figure 1 for a sketch of a typical price path). Their experiment has been replicated many times and with a large number of robustness checks.

It is not easy to explain those results. A first feature of the experiments in this literature is that there are dividends after each trading period. A second, and of course related feature is that the fundamental value of the asset is declining throughout the experiment. Clearly, both features are not typical for real financial markets. While dividend payments certainly are one possible factor to explain bubbles in some real financial markets, they cannot account for bubbles in many other markets. For example, some dot-com stocks, which arguably experienced on of the most pronounced bubbles in history, never paid dividends (e.g. Dell, Yahoo!, Oracle). Also, commodities do not pay dividends but experience bubbles nevertheless. Furthermore, 


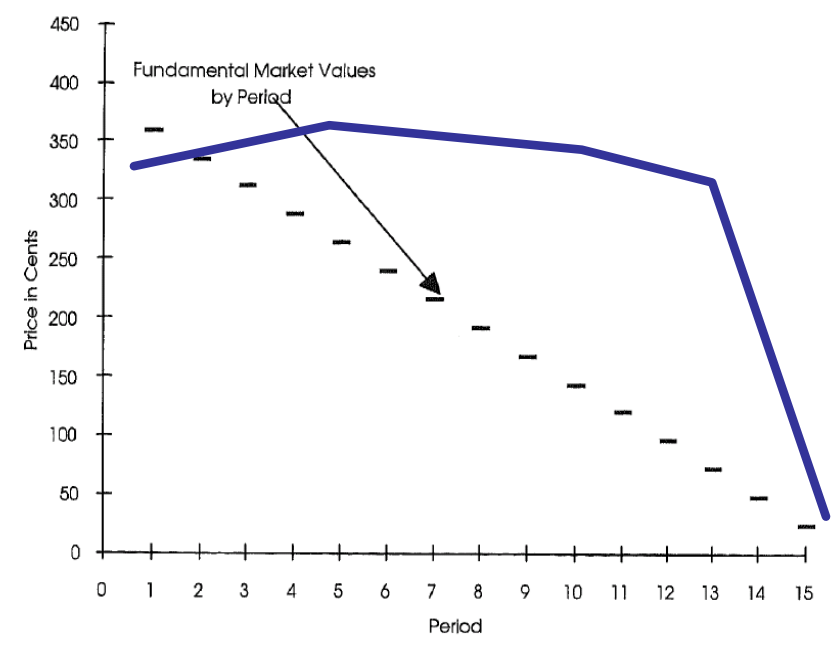

Figure 1: A relatively typical price path in a market with falling fundamental value (the funamental value is given by the step function)

dividends for most stocks are paid out only once per year, which could only explain a very slow formation of bubbles. Thus, it seems that dividend payments can only be a partial explanation for the formation of bubbles in real financial markets.

Vernon Smith is quite right in blaming a failure of backward induction for the existence of bubbles in these simple experimental markets. Subjects apparently don't make the leap from the last period, in which the asset loses all its value as there are no further dividends, to the second last period to the third last period etc. But who can blame them? Are these experiments typical of real asset markets? Backward induction is only useful when there is a finite number of periods which most asset markets don't have. Subjects are told that they trade assets on a market so they probably expect to see something similar to what they see on real markets: stochastic processes with increasing or at least constant trend in most cases.

I guess it's fair to say that the literature still has no persuasive explanation why bubbles occur in markets with declining fundamental value. And 
I can offer no convincing explanation either apart from agreeing with Vernon Smith that confusion of subjects probably plays a role. Thus, the large body of literature may be more about the ability of subjects to backward induct and calculate expected values than about asset markets. One could argue that - since there is still no generally accepted explanation - we need more research and more experiments in this direction. And in a world without scarcity we could do just that. But with scarcity, wouldn't it be more productive to run experiments with more realistic features? What about asset markets with constant fundamental values, what about communication among traders, what about several assets, what about a mixture of informed and uninformed agents? And given current events, what about incorporating a "bailout" probability?

I believe we need such explorations into the "shady areas", into regions that are not so well-lit by earlier experiments. We also need experimental protocols that make sure that results are not driven mainly by confusion of subjects. As Vernon Smith (2010) aptly observes subjects often "do not get the message we thought should be transparent" from the instructions. That is, we need instructions that explain settings in plain language and we need tests that make sure that subjects understand the instructions. But I also think we need to allow subjects the time to learn through experience because I fully concur with Smith when he states that "people learn primarily by doing, or observing others doing, not by deliberation and abstract analysis."

\section{Conclusion}

Some of the best known experiments, which are discussed and cited in numerous other papers, which are replicated and modified in minor design details, are cute, intellectually interesting but largely irrelevant. I would argue that we as economists can gain more from experiments that focus on economically relevant questions, even if this sometimes requires a fairly large step from existing experimental paradigms - away from the lamppost and into the shadow. 


\section{References}

Oechssler, J., Roider, A., Schmitz, P., 2008. Cooling-off in negotiations Does it work? mimeo, University of Heidelberg.

Oxoby, R., Spraggon, J., 2008. Mine and yours: Property rights in dictator games. Journal of Economic Behavior and Organization 65, 703-713.

Smith, V., Suchanek, G., Williams, A., 1988. Bubbles, crashes, and endogenous expectations in experimental spot asset markets. Econometrica 56, 1119-1151.

Smith, V., 2010. Theory and experiments: What are the questions? Journal of Economic Behavior and Organization, this issue. 